\title{
Importance of Genotype on Carotenoid and Chlorophyll Levels in Broccoli Heads
}

\author{
Mark W. Farnham ${ }^{1,3}$ \\ U.S. Department of Agriculture, Agricultural Research Service, U.S. Vegetable \\ Laboratory, 2700 Savannah Highway, Charleston, SC 29414 \\ Dean A. Kopsell ${ }^{2}$ \\ Plant Sciences Department, University of Tennessee, Knoxville, TN 37996- \\ 4561
}

Additional index words. Brassica oleracea-Italica Group, lutein, $\beta$-carotene, violaxanthin, antheraxanthin, neoxanthin, antioxidant

\begin{abstract}
Carotenoids are secondary plant metabolites in vegetables known to be essential in the human diet and reported to confer various positive health-promoting effects when consumed. Brassica oleracea $L$. vegetables like kale, cabbage, and broccoli are recognized as excellent sources of dietary carotenoids. Broccoli has emerged as the most important B. oleracea crop in the United States and it likely supplies more carotenoids to the U.S. diet than the other crops of this species. However, very little is known about the general carotenoid profile of this important vegetable or the levels of specific carotenoids and how they might vary among genotypes. Thus, the objectives of this study were to assess carotenoid profiles of different inbred broccoli heads; to assess chlorophyll concentrations measured simultaneously during carotenoid assays; to determine the relative effects of genotype versus environment in influencing head carotenoid levels; and to examine phenotypic correlations between carotenoid levels and other traits. Results show lutein to be the most abundant carotenoid in broccoli heads ranging from 65.3 to 139.6 $\mu \mathrm{g} \cdot \mathrm{g}^{-1}$ dry mass (DM) among nine inbreds tested in three environments. Genotype had a highly significant effect on lutein levels in broccoli heads and the ratio of $\sigma^{2}{ }_{\mathrm{g}} / \sigma^{2}$ for this carotenoid was 0.84 . Violaxanthin also exhibited a significant genotype effect, but it was found at lower levels (17.9 to $\left.35.4 \mu \mathrm{g} \cdot \mathrm{g}^{-1} \mathrm{DM}\right)$ than lutein. $\beta$-carotene and neoxanthin were detected at levels similar to violaxanthin, but genotypic differences were not detected when all environments were compared. This was also true for antheraxanthin, which was detectable in all genotypes at lower levels (mean of $13.3 \mu \mathrm{g} \cdot \mathrm{g}^{-1} \mathrm{DM}$ ) than the other carotenoids. Significant genotypic differences were observed for both chlorophyll a and $b$ among the studied inbreds; however, no environment or genotype-by-environment effects were observed with these compounds. Results indicated that most carotenoids measured were positively and significantly correlated with one another, indicating that higher levels of one carotenoid were typically associated with higher levels of others. This study emphasizes the relative importance of lutein in broccoli heads and the key role that genotype plays with this compound, ultimately indicating that breeding cultivars with increased levels of this particular carotenoid may be feasible.
\end{abstract}

Carotenoids are lipid-soluble, secondary plant metabolites in vegetables reported to confer positive health-promoting effects when consumed in the diet (Kopsell and Kopsell, 2006). Two nutritionally important, plantderived carotenoids are lutein $\left(3 \mathrm{R}, 3^{\prime} \mathrm{R},-\right.$ $6^{\prime} \beta, \varepsilon-$ carotene- $3,3^{\prime}$ diol), an oxygenated xanthophyll, and $\beta$-carotene ( $\beta, \beta$-carotene), a hydrocarbon carotene. $\beta$-carotene and also zeaxanthin, antheraxanthin, violaxanthin, and neoxanthin are a group of carotenoids that contain two $\beta$-rings, and lutein as well as $\alpha$-carotene are carotenoids with one $\beta$-ring and one $\varepsilon$-ring (Cunningham, 2002). In

Received for publication 4 Mar. 2009. Accepted for publication 20 May 2009.

${ }^{1}$ Research Geneticist.

${ }^{2}$ Associate Professor.

${ }^{3}$ To whom reprint requests should be addressed; e-mail Mark.Farnham@ars.usda.gov. plants, carotenoids span thylakoid membranes of chlorophyll (Chl) complexes and function in accessory roles for light harvesting, photoprotection, and structural stabilization (Demmig-Adams et al., 1996; Tracewell et al., 2001). These pigments protect photosynthetic structures by quenching excited triplet $\mathrm{Chl}\left({ }^{3} \mathrm{Chl}\right)$ to dissipate excess energy and by binding singlet oxygen $\left({ }^{1} \mathrm{O}_{2}\right)$ to inhibit potential oxidative damage (Frank and Cogdell, 1996; Tracewell et al., 2001).

Plant carotenoids are the most important source of provitamin A in the human diet. There is increasing evidence that these carotenoids can protect humans against certain specific chronic ailments, including cancer, cardiovascular disease, and age-related macular degeneration (Giovannucci, 1999; Mayne, 1996). From a dietary standpoint, carotenoids are common examples of compounds classified as antioxidants. The impor- tant role that carotenoids perform in plants, and the potential positive benefit they impart on human health, has stimulated increased interest in this important group of secondary plant metabolites (DellaPenna and Pogson, 2006; Hirschberg, 2001). Although this increased interest has resulted in a good understanding of the biosynthetic pathways that generate an array of important carotenoids in plants (Kopsell and Kopsell, 2006), the regulatory means by which different plants affect variable levels of individual carotenoids largely remains a mystery.

The thorough study of the carotenoid biosynthetic pathway has resulted in the characterization of numerous biosynthetic genes that can be used to engineer plants to produce altered carotenoid profiles and levels (Fraser and Bramley, 2004). Examples of such genetic engineering include golden rice (Ye et al., 2000) and yellow potatoes (Ducreux et al., 2005). Although genetic transformations such as these and others have helped enhance our understanding of carotenoid biosynthesis, the use of resulting new plant types remains problematic as a result of questions about the consumption of transgenic plants. This is especially likely to remain a significant concern for vegetables through the foreseeable future.

Carotenoid accumulation in plant tissue is generally determined by an interaction of physiological, biochemical, and genetic characteristics of a plant species as well as by environmental factors (Goldman et al., 1999; Kopsell et al., 2004, 2005; Kurilich et al., 1999). It is not surprising that different vegetable species can have dramatically different carotenoid profiles (Kimura and RodriguezAmaya, 2003; Klein and Perry, 1982; Sommerburg et al., 1998), but variation among different genotypes within a species (Kurilich et al., 1999) or crop (Kopsell et al., 2005) can also be very significant.

Brassica oleracea L. vegetables are recognized as good sources of dietary carotenoids (USDA Nutrient Database, 2008). Indeed, kale (B. oleracea L. var. viridis) ranks as having the highest carotenoid levels of all leafy vegetable crops assayed to date (Sommerburg et al., 1998). Kopsell et al. (2004) reported lutein levels in kale ranging from 4.8 to $13.4 \mathrm{mg} / 100 \mathrm{~g}$ fresh weight (FW) and showed that cultigen (genotype) and season of production had significant effects on lutein concentration. They also observed that genotype and season both had a significant effect on $\beta$-carotene levels, which ranged from 3.8 to $10.0 \mathrm{mg} / 100 \mathrm{~g} \mathrm{FW}$. Kopsell et al. (2004) did not observe a significant genotype-by-season interaction for either lutein or $\beta$-carotene. Kurilich et al. (1999) examined $\alpha$-carotene and $\beta$-carotene levels of broccoli (B. oleracea var. italica Plenck) heads harvested from a single field trial and demonstrated a significant genotype effect on levels of both carotenoids. $\beta$-carotene was much more prevalent in broccoli samples tested ranging from 0.4 to $2.4 \mathrm{mg}$ / $100 \mathrm{~g} \mathrm{FW}$. $\alpha$-carotene was only detected at levels from 0.0 to just under $0.1 \mathrm{mg} / 100 \mathrm{~g}$ 
FW. No comparisons of $\alpha$ - or $\beta$-carotene levels in heads harvested from different environments were made in this study.

Another cole crop receiving significant attention at this time with regard to carotenoid content is orange cauliflower ( $B$. oleracea L. var. botrytis), a unique genotype that has been around for several years (Crisp et al., 1975; Dickson et al., 1988). This phenotype occurs as a spontaneous mutant conditioned by the $O r$ (orange) gene, which operates in a semidominant manner and ultimately results in abnormally high levels of $\beta$-carotene in developing curds ( $\mathrm{Li}$ et al., 2001, 2006). Although the Or mutant is a useful tool for studying carotenoid biosynthesis in cole crops (Lu et al., 2006), cauliflower harvested from such mutants represents only a fraction of the standard cauliflower market, and it is sold exclusively as a niche product. Moreover, information generated from this mutant has not shed much light on our understanding of intervarietal genetic variation for levels of individual carotenoids.

Broccoli has emerged as the most important cole crop in the United States. Recent production statistics indicate that it may be among the top five vegetable crops in the country with a farm-gate value over $\$ 600$ million (USDA National Agricultural Statistics Service, 2008). As a result of its relative importance compared with other cole crops like cabbage and cauliflower, broccoli likely supplies more carotenoids to the U.S. diet than any other cole crop. However, very little is known about the general carotenoid profile of this important vegetable or the levels of specific carotenoids and how they might vary among genotypes. With this in mind, the objectives of this study were to assess carotenoid profiles of broccoli heads harvested from a set of inbred broccoli lines grown in three environments; to determine the relative effects of genotype versus environment in influencing what levels of measurable carotenoids are expressed in harvested heads; and to examine phenotypic correlations between carotenoid levels and other horticultural traits. Because $\mathrm{Chl}$ a and $\mathrm{b}$ can be measured simultaneously using techniques to assess carotenoids and because there is some recent evidence (Ferruzzi and Blakeslee, 2007) that $\mathrm{Chl}$ consumption might be linked to a chemoprotective effect, we had an additional objective to evaluate $\mathrm{Chl} \mathrm{a}$ and $\mathrm{b}$ and any possible relationships with carotenoid concentrations.

\section{Materials and Methods}

Plant materials. Nine homozygous inbred (doubled haploid) lines of broccoli were tested in these studies. These nine lines are relatively elite parental lines that have been used in several studies conducted by the U.S. Vegetable Laboratory broccoli breeding program, and they were selected to represent diverse genotypes and phenotypes. In particular, they have been used to develop a diallel population to study combining ability (Abercrombie et al., 2005) and heterosis
(Hale et al., 2007) for several economically important horticultural traits of broccoli. The included lines have the following designations and origins: USVL105 derived from 'Arcadia' (Sakata Inc., Morgan Hill, CA); USVL066 derived from 'Viking' (originally from Peto Seeds, Saticoy, CA); USVL039 derived from 'High Sierra' (originally from Asgrow, San Juan Bautista, CA); USVL032 derived from 'Green Valiant' (Sakata Inc.); USVL047 and USVL048 derived from 'Marathon' (Sakata Inc.); USVL012 and USVL089 derived from 'Everest' (Syngenta Seed Co., Gilroy, CA); and USVL070 derived from 'Futura' (Asgrow).

Plant culture and harvest. Three field trials were planted into randomized complete block designs with three replications at Charleston, SC. In the first week of Aug. 2001 and 2003, the nine doubled haploid lines were seeded into a commercial potting mix (Metromix 200; Scotts-Sierra Horticultural Products, Marysville, $\mathrm{OH}$ ) into 200-cell trays (Speedling Inc., Sun City, FL) in a greenhouse receiving no supplemental light with temperatures ranging from 25 to $30^{\circ} \mathrm{C}$, and seedlings were transplanted to the field on 19 Sept. in both years. Soil type for the Fall 2001 trial was a Yonges loamy fine sand and for Fall 2003 a Hockley loamy fine sand. On 1 Feb. 2003, the same nine lines were seeded to the same trays in the greenhouse and then transplanted to the field (Yonges) on $27 \mathrm{Feb}$. Individual plots consisted of 12 plants of an individual entry. Previously described cultural practices were followed for all three trials (Farnham et al., 2000).

As plots approached maturity, they were observed every $2 \mathrm{~d}$, and those heads that had reached 10 to $12 \mathrm{~cm}$ in diameter were evaluated for quality traits and then harvested. Three heads per plot were sampled at random, and subtending stalks were cut to a 16$\mathrm{cm}$ length. Sampled heads were weighed and stem diameter of the cut stem was measured. Harvested heads were immediately placed on ice in the field and within $\approx 30 \mathrm{~min}$ of field harvest, florets were cut from the stem, placed in an individual sealable freezer bag, and frozen at $-80{ }^{\circ} \mathrm{C}$. Sample dates were recorded for calculation of the mean number of days from transplant to harvest (DTH) on a plot basis. In addition to this sampling, horticultural traits (i.e., plant height and width, head position, firmness, color, bead size, etc.) were recorded on a total of six plants per plot. Individual plant measurements were averaged to compute a plot mean for each trait.

After all heads were harvested from the experiment, frozen florets were lyophilized for no less than $96 \mathrm{~h}$ (model $12 \mathrm{~L}$ FreeZone; LabConCo, Kansas City, MO), ground into a fine powder using coffee grinding mills, and then returned to freezer storage at $-80{ }^{\circ} \mathrm{C}$ until extraction and analysis was conducted.

Tissue extraction. Pigments were extracted from freeze-dried tissues according to Kopsell et al. (2004) and analyzed according to Emenhiser et al. (1996). A tissue subsample was rehydrated with $0.8 \mathrm{~mL}$ of ultrapure $\mathrm{H}_{2} \mathrm{O}$ and placed in a water bath set at $40{ }^{\circ} \mathrm{C}$ for $20 \mathrm{~min}$. After incubation, $0.8 \mathrm{~mL}$ of the internal standard ethyl- $\beta-8^{\prime}$ apo-carotenoate (Sigma Chemical Co., St. Louis, MO) was added to determine extraction efficiency. The addition of $2.5 \mathrm{~mL}$ of tetrahydrofuran (THF) stabilized with 25 $\mathrm{mg} \cdot \mathrm{L}^{-1}$ of 2,6-Di-tert-butyl-4-methoxyphenol was performed after sample hydration. The sample was then homogenized in a PotterElvehjem (Kontes, Vineland, NJ) tissue grinding tube using $\approx 25$ insertions with a pestle attached to a drill press (Sears, Roebuck and Co., Hoffman Estates, IL) set at 540 rpm. During homogenation, the tube was immersed in ice to dissipate heat. The tube was then placed into a clinical centrifuge for $3 \mathrm{~min}$ at $500 \mathrm{~g}_{\mathrm{n}}$. The supernatant was removed and the sample pellet was resuspended in $2 \mathrm{~mL}$ THF and homogenized again with the same extraction technique. The procedure was repeated for a total of four extractions to obtain a colorless supernatant. The combined supernatants were reduced to $0.5 \mathrm{~mL}$ under a stream of nitrogen gas $(\mathrm{N}$ EVAP 111; Organomation Inc., Berlin, MA) and brought up to a final volume of $5 \mathrm{~mL}$ with methanol $(\mathrm{MeOH})$. A 2-mL aliquot was filtered through a $0.2-\mu \mathrm{m}$ polytetrafluoroethylene filter (Model Econofilter PTFE 25/ 20; Agilent Technologies, Wilmington, DE) using a 5-mL syringe (Becton, Dickinson and Company, Franklin Lakes, NJ) before highperformance liquid chromatography (HPLC) analysis.

High-performance liquid chromatography analysis. An Agilent 1200 series HPLC unit with a photodiode array detector (Agilent Technologies) was used for pigment separation. Chromatographic separations were achieved using an analytical scale $(4.6 \mathrm{~mm}$ i.d. $\times 250 \mathrm{~mm}), 5 \mu \mathrm{m}, 200 \AA$ polymeric $\mathrm{C}_{30}$ reverse-phase column (ProntoSIL, MACMOD; Analytical Inc., Chadds Ford, PA), which allowed for effective separation of chemically similar pigment compounds. The column was equipped with a guard cartridge $(4.0 \mathrm{~mm}$ i.d. $\times 10 \mathrm{~mm})$ and holder (ProntoSIL) and was maintained at $30{ }^{\circ} \mathrm{C}$ using a thermostatted column compartment. All separations were achieved isocratically using a binary mobile phase of $11 \%$ methyl tert-butyl ether, $88.9 \% \mathrm{MeOH}$, and $0.1 \%$ triethylamine $(\mathrm{v} / \mathrm{v} / \mathrm{v})$. The flow rate was 1.0 $\mathrm{mL} \cdot \mathrm{min}^{-1}$ with a run time of $55 \mathrm{~min}$ followed by a 2-min equilibration before the next injection. Eluted compounds from a $10-\mu \mathrm{L}$ injection were detected at 453 (carotenoids and internal standard), 652 (Chl a), and 665 (Chl b) $\mathrm{nm}$ and data were collected, recorded, and integrated using ChemStation Software (Agilent Technologies). Peak assignment for individual pigments was performed by comparing retention times and line spectra obtained from photodiode array detection using external standards (antheraxanthin, $\beta$-carotene, Chl a, Chl b, lutein, neoxanthin, violaxanthin, zeaxanthin from ChromaDex Inc., Irvine, CA). Spinach standard reference material (Slurried Spinach 2385; National Institute of Science and Technology, 
Gaithersburg, MD) was used for method validation. Pigment data are presented on a dry mass (DM) basis.

Every effort was made to reduce any effects of light and/or thermal degradation during extraction and HPLC analysis. The laboratory has no windows and only fluorescent lighting (low light intensity and limited wavelengths below $400 \mathrm{~nm}$ ), so extractions were carried out under reduced light. In addition, exposure to all light was reduced during extraction by placing solutions under cover in ice baths. Samples were also filtered into amber HPLC vials that exclude light and protected when run on the HPLC by a tinted shield covering the autosampler.

Statistical analysis. Results from each individual environment were first analyzed as separate experiments to examine entry effects on carotenoid levels and other traits. Data from the three trials were then combined to examine environment and genotypeby-environment interactions. Analysis of variance was performed using Proc GLM of SAS (Release 9.1; SAS Institute, Inc., Cary, NC). Genotype and environment were treated as random effects. Mean squares resulting from analysis of variance were used to estimate individual components of variance for genotype and genotype by environment (Table 1) using methods described by Fehr (1987). Pearson's correlation coefficients were also calculated for all pairwise comparisons between measured compounds and horticultural traits.

\section{Results and Discussion}

Examination of the horticultural attributes of the nine doubled haploid broccoli lines used in this study readily shows they represent a diverse set of homozygous lines (Table 2). This is illustrated by mean expression of maturity (DTH), head weight, and stem diameter averaged across all three environments. Mean maturity of the tested lines ranged from 68.6 to $104.1 \mathrm{DTH}$, head weight ranged from 142.4 to $252.6 \mathrm{~g}$ per head, and stem diameter from 29.6 to $35.9 \mathrm{~mm}$ (Table 2). Phenotypic differences like these are underlined by significant genotypic differences previously reported for the same inbred lines (Hale et al., 2007).

Nearly $100 \%$ of broccoli consumed in North America and Europe is harvested from $\mathrm{F}_{1}$ hybrid cultivars. Although a broccoli breeder's ultimate target is an elite hybrid, he or she conducts a significant portion of the breeding process, including making selec-

Table 1. Expected mean squares and df for analysis of variance of carotenoid concentrations and other traits measured on inbred broccoli genotypes grown in three environments.

\begin{tabular}{lcl}
\hline Source & Degrees of freedom & \multicolumn{1}{c}{ Expected mean squares } \\
\hline Environment (E) & $\mathrm{t}-1$ & $\sigma^{2} \mathrm{e}+\mathrm{g} \sigma_{\mathrm{R} / \mathrm{E}}^{2}+\mathrm{rg} \sigma_{\mathrm{E}}^{2}+\mathrm{r} \sigma_{\mathrm{GE}}^{2}$ \\
Replication/E & $(\mathrm{r}-1) \mathrm{t}$ & $\sigma^{2} \mathrm{e}+\mathrm{g} \sigma_{\mathrm{R} / \mathrm{E}}^{2}$ \\
Genotype (G) & $\mathrm{g}-1$ & $\sigma^{2} \mathrm{e}+\mathrm{r}_{\sigma_{\mathrm{GE}}^{2}}+\mathrm{rt \sigma ^{2 }}$ \\
$\mathrm{G} \times \mathrm{E}$ & $(\mathrm{g}-1)(\mathrm{t}-1)$ & $\sigma^{2} \mathrm{e}+\mathrm{r} \sigma_{\mathrm{GE}}^{2}$ \\
Error $(\mathrm{e})$ & $(\mathrm{g}-1)(\mathrm{r}-1) \mathrm{t}$ & $\sigma^{2} \mathrm{e}$ \\
Total & $(\mathrm{r})(\mathrm{t})(\mathrm{g})-1$ & \\
\hline
\end{tabular}

$\mathrm{z}_{\mathrm{t}}=$ number of environments; $\mathrm{r}=$ number of replications; $\mathrm{g}=$ number of genotypes.

tions from segregating populations during the inbreeding phase. For the most part, new hybrid combinations typically result from the use of new inbred parents in new cross-combinations. Therefore, if a breeder is to affect changes in any trait (e.g., carotenoid content) at the hybrid level, it is first important to understand how those traits are exhibited among homozygous inbred lines.

There were significant genotype effects on levels of both Chl a and Chl b in broccoli heads among the tested lines (Table 3). However, no significant environmental or genotype-by-environment effects were observed for concentrations of either of the Chls. In general, this reflects very similar rankings of the different lines for Chl concentrations of heads in all three environments. Among the nine lines analyzed, USVL039 had lowest Chl a concentration of $295.3 \mu \mathrm{g} \cdot \mathrm{g}^{-1} \mathrm{DM}$, whereas USVL070 was highest at $539.5 \mu \mathrm{g} \cdot \mathrm{g}^{-1} \mathrm{DM}$ (Table 4). Chl b concentration was lower than that of $\mathrm{Chl}$ a, ranging from 185.6 to $377.6 \mu \mathrm{g} \cdot \mathrm{g}^{-1} \mathrm{DM}$ (Table 4). These results are somewhat different from those observed for kale by Kopsell et al. (2004), in which they observed significant environmental and genotype-byenvironment effects. It is possible that $\mathrm{Chl}$ concentrations of kale leaves, which have much greater levels than broccoli heads, are more likely influenced by environmental cues in general or more prone to exhibit interactions between particular genotypes and possible environmental conditions. Differences may also reflect the photosynthetic capacity of leaf tissues (kale) versus immature floret tissues (broccoli).

Associations of increased fruit and vegetable consumptions with the prevention of chronic diseases have led to new investigations into the roles of Chls as valuable phytochemicals. A recent review by Ferruzzi and Blakeslee (2007) characterizes potential health benefits associated with dietary natural $\mathrm{Chl}$ and $\mathrm{Chl}$ derivatives. Although $\mathrm{Chl}$ and its derivatives have long been used in traditional medicines for therapeutic purposes (Kephart, 1955), data on bioavailability and preventative activities have been lacking in part as a result of the assumption that $\mathrm{Chl}$ is unabsorbable by humans. Recent evidence is suggesting that dietary Chls may possess biological activities associated with cancer preventions, antimutagenic activities, and induction of apoptosis in tumor cells (Egner et al., 2001, 2003). Moreover, recent epidemiological data have linked dietary Chls with reduced risks of colon cancer in humans (Balder et al.,
Table 2. Trait means for days from transplant to harvest (DTH), individual head mass, and stem diameter of harvested heads for nine inbred genotypes averaged across three test environments used in this study.

\begin{tabular}{lrcc}
\hline Genotype & DTH & $\begin{array}{c}\text { Head mass } \\
\text { (g fresh weight) }\end{array}$ & $\begin{array}{c}\text { Stem diam } \\
(\mathrm{mm})\end{array}$ \\
\hline USVL070 & 68.6 & 142.4 & 32.6 \\
USVL012 & 71.1 & 197.6 & 35.9 \\
USVL089 & 71.8 & 174.1 & 29.6 \\
USVL047 & 76.1 & 211.2 & 35.6 \\
USVL105 & 86.4 & 208.7 & 34.7 \\
USVL032 & 86.7 & 197.1 & 35.6 \\
USVL039 & 91.0 & 168.4 & 30.8 \\
USVL048 & 91.7 & 252.6 & 34.3 \\
USVL066 & 104.1 & 164.6 & 32.6 \\
LSD 0.05 & 6.0 & 22.5 & 4.1 \\
\hline
\end{tabular}

2006). Alternatively, limited intestinal absorption may result in Chls to facilitate sequestration of potential mutagens and carcinogens, thereby limiting their uptake and potential damaging effects (Hartman and Shankel, 1990; Natsume et al., 2004). New investigations on the health properties of Chls are underway and may soon establish their values as dietary components in green vegetables such as broccoli.

The most prevalent carotenoid in broccoli heads is lutein. In this study, lutein exhibited significant $(P<0.05)$ effects as a result of environment and genotype-by-environment interaction; however, these effects were relatively small compared with the significant $(P<0.01)$ effect as a result of genotype (Table 3). Mean lutein concentration ranged from a low $65.3 \mu \mathrm{g} \cdot \mathrm{g}^{-1} \mathrm{DM}$ for USVL048 to a high of $139.6 \mu \mathrm{g} \cdot \mathrm{g}^{-1}$ DM for USVL070 (Table 4). Lutein functions as an integral subunit of light-harvesting complexes in photosynthesis. In plant mutants void of xanthophyll cycle carotenoids, lutein functions in nonphotochemical quenching as a photoprotectant against oxidative damage (Niyogi et al., 1997). The only previous report (Kurilich et al., 1999) focusing on broccoli carotenoids measured levels of $\alpha$-carotene and $\beta$-carotene, but not lutein. The picture for total carotenoid concentration in broccoli heads was parallel with that for lutein (Table 3 ); this is largely because $50 \%$ or more of total carotenoids can be accounted for by lutein. Violaxanthin levels in broccoli heads were much lower than those for lutein (Table 4), but this particular carotenoid also exhibited a significant genotype effect (Table 3 ). Unlike lutein, however, effects of environment and genotype by environment were nonsignificant. Lowest mean violaxanthin concentration (17.9 $\left.\mu \mathrm{g} \cdot \mathrm{g}^{-1} \mathrm{DM}\right)$ was also observed for heads of USVL048. The highest concentration $\left(35.4 \mu \mathrm{g} \cdot \mathrm{g}^{-1} \mathrm{DM}\right)$ of violaxanthin was observed for USVL032.

It is useful to examine results for the trait DTH, which is a relative measure of maturity and known to be highly heritable (Abercrombie et al., 2005; Brown et al., 2007; Hulbert and Orton, 1984). With this trait, there was no environmental effect and although genotype by environment was significant $(P<0.01)$, the relative importance of the genotype effect 
Table 3. Mean squares from the analysis of variance of concentrations $\left(\mu \mathrm{g} \cdot \mathrm{g}^{-1} \mathrm{DM}\right)$ of chlorophyll a $(\mathrm{Ch}$ a), chlorophyll b (Chl b), violaxanthin, lutein, and total carotenoids (Total Car.) on a dry mass (DM) basis and also of days from transplant to harvest (DTH) for broccoli inbred genotypes $(\mathrm{G})$ grown in three environments $(\mathrm{E})$

\begin{tabular}{|c|c|c|c|c|}
\hline \multirow[b]{2}{*}{ Source } & \multirow[b]{2}{*}{ df } & Chl a & Chl b & DTH \\
\hline & & \multicolumn{3}{|c|}{ 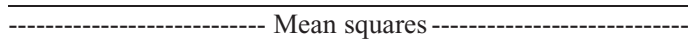 } \\
\hline Environment (E) & 2 & $286,092.13$ & $9,131.80$ & 102.27 \\
\hline Rep (E) & 6 & $84,186.36$ & $34,146.29 *$ & $107.98^{*}$ \\
\hline Genotype (G) & 8 & $123,908.89^{*}$ & $46,666.12 *$ & $1275.14 * *$ \\
\hline $\mathrm{G} \times \mathrm{E}$ & 16 & $37,694.99$ & $11,505.14$ & $160.80 * *$ \\
\hline Error & 48 & $38,243.46$ & $12,184.72$ & 39.70 \\
\hline Total & 80 & & & \\
\hline \multirow[t]{3}{*}{$\sigma_{\mathrm{g}}^{2} / \sigma_{\mathrm{p}}^{2}$} & & 0.69 & 0.75 & 0.87 \\
\hline & & Violaxanthin & Lutein & Total Car. \\
\hline & & \multicolumn{3}{|c|}{ 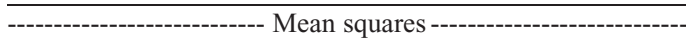 } \\
\hline$\overline{\mathrm{E}}$ & 2 & 131.51 & $2,014.39 *$ & $4,156.00$ \\
\hline Rep (E) & 6 & $238.10^{*}$ & 331.19 & $8,661.30$ \\
\hline $\mathrm{G}$ & 8 & $276.27 *$ & $6,539.59 * *$ & $16,046.36^{*}$ \\
\hline $\mathrm{G} \times \mathrm{E}$ & 16 & 73.47 & $1,036.99 *$ & $3,376.14 *$ \\
\hline Error & 48 & 60.01 & 507.63 & $1,781.08$ \\
\hline Total & 80 & & & \\
\hline$\underline{\sigma_{g}^{2} / \sigma_{p}^{2}}$ & & 0.73 & 0.84 & 0.79 \\
\hline
\end{tabular}

Table 4. Mean concentrations of total carotenoids, lutein, violaxanthin, chlorophyll a (Chl a), and chlorophyll b ( Chl b) for nine inbred genotypes across three test environments used in this study.

\begin{tabular}{|c|c|c|c|c|c|}
\hline \multirow[b]{2}{*}{ Genotype } & Total carotenoids & Lutein & Violaxanthin & Chl a & $\overline{C h l ~ b}$ \\
\hline & \multicolumn{5}{|c|}{ 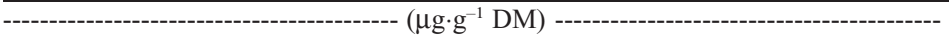 } \\
\hline$\overline{\text { USVL070 }}$ & 253.9 & 139.6 & 26.6 & 539.5 & 360.2 \\
\hline USVL066 & 246.6 & 134.4 & 30.3 & 266.0 & 310.7 \\
\hline USVL032 & 241.0 & 122.0 & 35.4 & 545.0 & 377.6 \\
\hline USVL012 & 236.2 & 138.9 & 30.6 & 435.6 & 335.0 \\
\hline USVL089 & 208.7 & 109.8 & 27.9 & 532.8 & 336.6 \\
\hline USVL039 & 175.2 & 93.7 & 22.5 & 295.3 & 185.6 \\
\hline USVL105 & 170.7 & 89.0 & 21.2 & 296.1 & 241.2 \\
\hline USVL047 & 169.8 & 84.1 & 22.4 & 339.1 & 224.0 \\
\hline USVL048 & 137.4 & 65.3 & 17.9 & 313.5 & 208.0 \\
\hline $\mathrm{LSD}_{0.05}$ & 40.4 & 21.4 & 7.3 & 185.4 & 104.6 \\
\hline
\end{tabular}

LSD $=$ least significant difference.

was much greater (Table 3). The ratio of genotypic variance to phenotypic variance $\left(\sigma_{\mathrm{g}}^{2} / \sigma_{\mathrm{p}}^{2}\right)$ was 0.87 and greater than that for all other traits examined here (Table 3 ). This ratio is similar to broadsense heritability, and relatively high values for this ratio (i.e., close to 1.0) indicate that genotype is an important component of observed phenotypic variation (Fehr, 1987). Our observed ratio (0.87) for DTH was nearly identical to a 0.84 ratio estimated by Brown et al. (2007) for the same trait. Among the other traits that exhibited a significant genotypic effect, lutein concentration had the next highest ratio at 0.84 indicating that genotype plays a significant role in expression of lutein concentration. Ratios of $\sigma_{\mathrm{g}}^{2} / \sigma_{\mathrm{p}}^{2}$ were 0.69 and 0.75 for levels of Chl a and $\mathrm{Chl} b$, respectively, 0.73 for violaxanthin, and 0.79 for total carotenoid concentrations. Although these latter ratios are less than those for DTH or lutein, they still indicate that two-thirds to three-fourths of phenotypic variation for these characters in broccoli heads can be attributed to genotype.

Table 5. Mean concentrations of $\beta$-carotene, neoxanthin, and antheraxanthin for nine inbred genotypes in each of three fall and spring test environments used in this study.

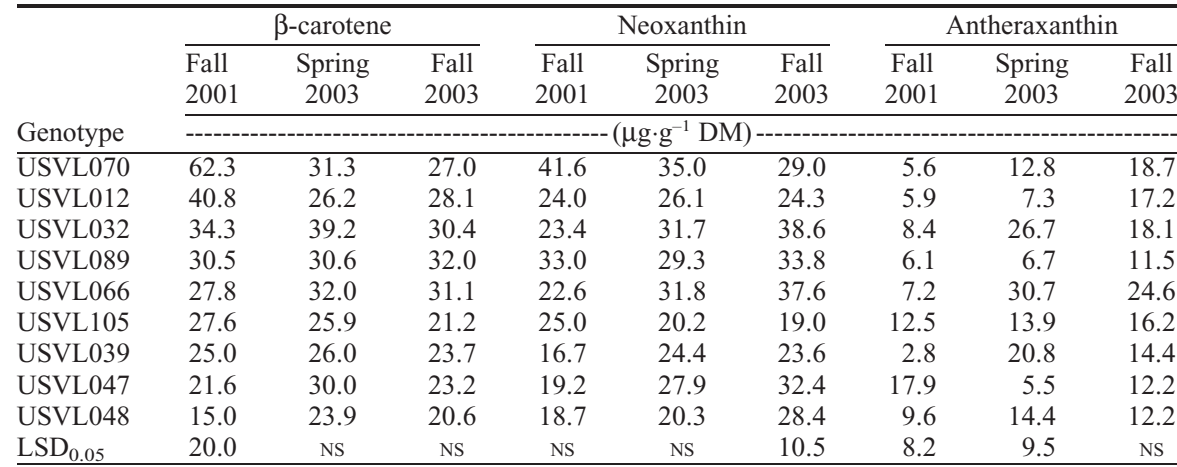

$\mathrm{DM}=$ dry mass; $\mathrm{NS}=$ nonsignificant. $\beta$-carotene and neoxanthin were detected at levels similar to those of violaxanthin (Table 5). However, genotypic differences for these two carotenoids were not detected when all three environments were compared in the analysis of variance (data not shown). When results from individual environments are examined, the effect of genotype was only significant for $\beta$-carotene in Fall 2001 when concentrations of this carotenoid ranged from $15.0 \mu \mathrm{g} \cdot \mathrm{g}^{-1} \mathrm{DM}$ for USVL048 to $62.3 \mu \mathrm{g} \cdot \mathrm{g}^{-1} \mathrm{DM}$ for USVL070 (Table 5). With neoxanthin, genotype was only significant in Fall 2003 when the observed range was from $19.0 \mu \mathrm{g} \cdot \mathrm{g}^{-1}$ DM for USVL105 to $38.6 \mu \mathrm{g} \cdot \mathrm{g}^{-1}$ DM for USVL032 (Table 5). Although antheraxanthin was detectable in all samples, it occurred at lower levels (mean of $13.3 \mu \mathrm{g} \cdot \mathrm{g}^{-1} \mathrm{DM}$ ) than all other carotenoids measured, and no genotype effect was observed for this compound across all three environments. However, genotype-byenvironment interaction was highly significant for this trait (data not shown). The xanthophyll cycle pigments (zeaxanthin, antheraxanthin, and violaxanthin) participate as antioxidants in light-harvesting complexes. Within the xanthophyll cycle, zeaxanthin is the primary carotenoid responsible for preventing photoinhibition; however, antheraxanthin has been reported to have similar photoprotective properties (Niyogi et al., 1997). Zeaxanthin and antheraxanthin can accumulate in high irradiance conditions as a result of the increased activity of the $\mathrm{pH}$ dependent enzyme violaxanthin de-epoxidase (Demmig-Adams et al., 1996). In two of three environments (Fall 2001 and Spring 2003) analyzed separately, antheraxanthin exhibited significant differences among genotypes (Table 5). For $\beta$-carotene, neoxanthin, and antherxanthin, computed ratios for $\sigma_{\mathrm{g}}^{2} / \sigma_{\mathrm{p}}^{2}$ were $0.51,0.66$, and 0.19 , respectively; estimates that are lower than those for lutein or violaxanthin.

Results from this study indicate that most of the carotenoids measured were positively and significantly correlated with one another (Table 6). In general, this indicates that higher levels of one carotenoid were often associated with higher levels of the others. The exception to this observation is antheraxanthin for which levels were not significantly correlated with other carotenoid levels. This may be a result of the fact that antheraxanthin tends to occur at relatively low levels compared with all others. $\mathrm{Chl} b$ exhibited a significant positive correlation with all carotenoids except antheraxanthin (Table 6). Chl a only exhibited similar correlations with violaxanthin, neoxanthin, and lutein (Table 6).

No carotenoid levels were correlated with DTH (data not shown); however, broccoli head mass (FW basis) was negatively correlated with the accumulation of individual and total carotenoid pigments (expressed on a DM basis; Table 6). Such negative correlations of carotenoid concentrations and broccoli head mass may occur as a result of increased biomass accumulation in certain 
Table 6. Correlation coefficients and levels of significance for comparisons of phenotypic means for characters measured on broccoli florets harvested from three test environments.

\begin{tabular}{|c|c|c|c|c|c|c|c|c|}
\hline & $\mathrm{Chl} \mathrm{b}$ & Violaxanthin & Neoxanthin & Antheraxanthin & Lutein & $\beta$-carotene & Total carotenoids & $\overline{\text { Head wt }}$ \\
\hline Chl a & $0.734 * * *$ & $0.445^{*}$ & $0.619 * * *$ & $-0.493 * *$ & $0.430^{*}$ & $0.189 \mathrm{NS}$ & $0.378 \mathrm{NS}$ & $-0.089 \mathrm{NS}$ \\
\hline Chl b & & $0.678 * * *$ & $0.696^{* * *}$ & $-0.022 \mathrm{NS}$ & $0.695 * * *$ & $0.577 * *$ & $0.722 * * *$ & $-0.345 \mathrm{NS}$ \\
\hline Violaxanthin & & & $0.606 * * *$ & $0.244 \mathrm{NS}$ & $0.751 * * *$ & $0.602 * * *$ & $0.832 * * *$ & $-0.394 *$ \\
\hline Neoxanthin & & & & $-0.010 \mathrm{NS}$ & $0.672 * * *$ & $0.611 * * *$ & $0.747 * * *$ & $-0.407^{*}$ \\
\hline Antheraxanthin & & & & & $0.075 \mathrm{NS}$ & $0.292 \mathrm{NS}$ & $0.274 \mathrm{NS}$ & $-0.001 \mathrm{NS}$ \\
\hline Lutein & & & & & & $0.702 * * *$ & $0.956 * * *$ & $-0.566^{* *}$ \\
\hline$\beta$-carotene & & & & & & & $0.825 * * *$ & $-0.580^{* *}$ \\
\hline Total carotenoids & & & & & & & & $-0.600 * * *$ \\
\hline
\end{tabular}

NS, ***,***Nonsignificant or significant at $P=0.05, P=0.01$, or $P=0.001$, respectively.

genotypes that is not accompanied by increased carotenoid production, effectively lowering the carotenoid concentration in the immature broccoli florets when pigments are expressed on a DM basis (Lefsrud et al., 2007) as they are in this study. In other trials conducted similar to this one, we have observed little variation in percent moisture of heads harvested from variable sets of broccoli genotypes. With heads processed rapidly from the field and harvested at 10 to $12 \mathrm{~cm}$ in diameter, percent moisture is always very close to $88 \%$ (unpublished data). This constant could be used to convert DM concentrations described here to FW concentrations.

To our knowledge, this study is the first to present a detailed examination of carotenoids in field-grown broccoli and the relative importance of genotype in influencing levels of specific carotenoid compounds. Previous research (Kurilich et al., 1999) presented some data on broccoli carotenoids, but it did not give any detailed characterization of the levels of violaxanthin, neoxanthin, antheraxanthin, or even lutein nor did it investigate the relative importance of genotype versus environment as described here. Indeed, this work emphasizes the relative importance of lutein and the key role that genotype plays with this compound, ultimately indicating that selection for this carotenoid might be plausible. Previous work focused on the $B$. oleracea subspecies kale (Kopsell et al., 2004) did examine the relative importance of genotype and environment; however, conclusions from a crop like kale that is consumed as a leaf cannot be expected to be the same as for a crop like broccoli, which is essentially a reproductive shoot. In addition, unlike kale for which some cultivars grown are still open-pollinated populations, commercial broccoli production is now conducted exclusively using $\mathrm{F}_{1}$ hybrids.

The first step in producing a new hybrid cultivar is to select the inbred parents that will be used in a cross. Relatively recent evidence (Abercrombie et al., 2005; Hale et al., 2007) emphasizes that performance per se of inbred broccoli lines for a variety of horticultural traits is an important criteria in determining which parents to select for making test hybrids. Results of this research indicate that selection among inbred broccoli based on broccoli head concentrations of certain carotenoids, like lutein, is likely to be effective. Future studies must determine whether general combining ability functions to affect broccoli carotenoid concentrations of hybrids as it does a variety of other important traits (Abercrombie et al., 2005; Hulbert and Orton, 1984).

\section{Literature Cited}

Abercrombie, J.M., M.W. Farnham, and J.W. Rushing. 2005. Genetic combining ability of glucoraphanin level and other horticultural traits of broccoli. Euphytica 143:145-151.

Balder, H.F., J. de Vogel, M.C.J.F. Jansen, M.P. Weijenberg, P.A. van den Brandt, S. Westenbrink, R. van der Meer, and R.A. Goldbohm. 2006. Heme and chlorophyll intake and risk of colorectal cancer in the Netherlands cohort study. Cancer Epidemiol. Biomarkers Prev. 15:717-725.

Brown, A.F., E.H. Jeffery, and J.A. Juvik. 2007. A polymerase chain reaction-based linkage map of broccoli and identification of quantitative trait loci associated with harvest date and head weight. J. Amer. Soc. Hort. 132:507513.

Crisp, P.D., G.A. Walkey, E. Bellman, and E. Roberts. 1975. Mutation affecting curd color in cauliflower (Brassica oleracea var. botrytis DC). Euphytica 24:173-176.

Cunningham, F.X., Jr. 2002. Regulation of carotenoid synthesis and accumulation in plants. Pure Appl. Chem. 74:1409-1417.

DellaPenna, D. and B.J. Pogson. 2006. Vitamin synthesis in plants: Tocopherols and carotenoids. Annu. Rev. Plant Biol. 57:711-738.

Demmig-Adams, B., A.M. Gilmore, and W.W. Adams III. 1996. In vivo functions of carotenoids in higher plants. FASEB J. 10:403412.

Dickson, M.H., C.Y. Lee, and A.E. Blamble. 1988. Orange-curd high carotene cauliflower inbreds, NY-156, NY-163, and NY-165. HortScience 23:778-779.

Ducreux, L.J.M., W.L. Morris, P.E. Hadley, T. Shepherd, H.V. Davies, S. Millam, and M.A. Taylor. 2005. Metabolic engineering of high carotenoid potato tubers containing enhanced levels of $\beta$-carotene and lutein. J. Expt. Bot. 56:81-89.

Egner, P.A., A. Munoz, and T.W. Kensler. 2003. Chemoprenention with chlorophyllin in individuals exposed to dietary aflatoxin. Mutat. Res. 523:209-216.

Egner, P.A., J.B. Wang, Y.R. Zhu, B.C. Zhang, Y. Wu, Q.N. Zhang, G.S. Qian, S.Y. Kuang, S.J. Gange, L.P. Jacobson, K.J. Helzlsouer, G.S. Bailey, J.D. Groopman, and T.W. Kensler. 2001. Chlorophyllin intervention reduces aflatoxin-DNA adducts in individuals at high risk for liver cancer. Proc. Natl. Acad. Sci. USA 98:14601-14606.

Emenhiser, C., N. Simunovic, L.C. Sander, and S.J. Schwartz. 1996. Separation of geometric carotenoid isomers in biological extracts using a polymeric $\mathrm{C}_{30}$ column in reverse-phase liquid chromatography. J. Agr. Food Chem. 44:38873893.

Farnham, M.W., M.A. Grusak, and M. Wang. 2000. Calcium and magnesium concentration of inbred and hybrid broccoli heads. J. Amer. Soc. Hort. Sci. 125:344-349.

Fehr, W.R. 1987. Principles of cultivar development. Vol. 1: Theory and technique. MacMillan Publishing Co., New York, NY.

Ferruzzi, M.G. and J. Blakeslee. 2007. Digestion, absorption, and cancer preventative activity of dietary chlorophyll derivatives. Nutr. Res. 27:1-12.

Frank, H.A. and R.J. Cogdell. 1996. Carotenoids in photosynthesis. Photochemistry 63:257-264.

Fraser, P.D. and P.M. Bramley. 2004. The biosynthesis and nutritional uses of carotenoids. Prog. Lipid Res. 43:228-265.

Giovannucci, E. 1999. Tomatoes, tomato-based products, lycopene, and cancer: Review of the epidemiologic literature. J. Natl. Cancer Inst. 91:317-331.

Goldman, I.L., A.A. Kader, and C. Heintz. 1999 Influence of production, handling, and storage on phytonutrient content of foods. Nutr. Rev. 57:S46-S52.

Hale, A.L., M.W. Farnham, M.N. Nzaramba, and C.A. Kimbeng. 2007. Heterosis for horticultural traits in broccoli. Theor. Appl. Genet. 115:351-360.

Hartman, P. and D. Shankel. 1990. Antimutagens and anticarcinogens: A survey of punitive interceptor molecules. Environ. Mol. Mutagen. 5:145-182.

Hirschberg, J. 2001. Carotenoid biosynthesis in flowering plants. Curr. Opin. Plant Biol. 4:210 218.

Hulbert, S. and T.J. Orton. 1984. Genetic and environmental effects on mean maturity date and uniformity in broccoli. J. Amer. Soc. Hort. Sci. 109:487-490.

Kephart, J.C. 1955. Chlorophyll derivativesTheir chemistry, commercial preparations, and uses. Econ. Bot. 9:3-38.

Kimura, M. and D.B. Rodriguez-Amaya. 2003. Carotenoid composition of hydroponic leafy vegetables. J. Agr. Food Chem. 51:26032607.

Klein, B.P. and A.K. Perry. 1982. Ascorbic acid and vitamin A activity in selected vegetables from different geographic areas of the United States. J. Food Sci. 47:941-948.

Kopsell, D.A. and D.E. Kopsell. 2006. Accumulation and bioavailability of dietary carotenoids in vegetable crops. Trends Plant Sci. 11:499507.

Kopsell, D.A., D.E. Kopsell, and J. Curran-Celentano. 2005. Carotenoid and chlorophyll pigments in sweet basil grown in the field and greenhouse. HortScience 40:1230-1233.

Kopsell, D.A., D.E. Kopsell, M.G. Lefsrud, J. Curran-Celentano, and L.E. Dukach. 2004. 
Variation in lutein, $\beta$-carotene, and chlorophyll concentrations among Brassica oleracea cultigens and seasons. HortScience 39:361364.

Kurilich, A.C., G.J. Tsau, A. Brown, L. Howard, B.P. Klein, E.H. Jeffery, M. Kushad, M.A. Wallig, and J.A. Juvik. 1999. Carotene, tocopherol, and ascorbate contents in subspecies of Brassica oleracea. J. Agr. Food Chem. 47: 1576-1581.

Lefsrud, M.G., D.A. Kopsell, and D.E. Kopsell. 2007. Nitrogen levels influence biomass, elemental accumulations, and pigment concentrations in spinach. J. Plant Nutr. 30:171185.

Li, L., S. Lu, K.M. Cosman, E.D. Earle, D.F. Garvin, and J. O’Neill. 2006. $\beta$-carotene accumulation induced by the cauliflower Or gene is not due to an increased capacity of biosynthesis. Phytochemistry 67:1177-1184.

Li, L., D.J. Paolillo, M.V. Parthasarathy, E.M. DiMuzio, and D.F. Garvin. 2001. A novel gene mutation that confers abnormal patterns of $\beta$-carotene accumulation in cauliflower (Bras- sica oleracea var. botrytis). Plant J. 26:5967.

Lu, S., J. Van Eck, X. Zhou, A.B. Lopez, D.M. O’Halloran, K.M. Cosman, B.J. Conlin, D.J. Paolillo, D.F. Garvin, J. Vrebalov, L.V. Kochian, H. Kupper, E.D. Earle, J. Cao, and L. Li. 2006. The cauliflower $O r$ gene encodes a DnaJ cysteine-rich domain-containing protein that mediates high levels of $\beta$-carotene accumulation. Plant Cell 18:3594-3605.

Mayne, S.T. 1996. $\beta$-carotene, carotenoids, and disease prevention in humans. FASEB J. 10:690-701.

Natsume, Y., H. Satsu, K. Kitamura, N. Okamoto, and M. Shimizu. 2004. Assessment system for dioxin absorption in the small intestine and prevention of its absorption by food factors. Biofactors 21:375-377.

Niyogi, K.K., O. Björkman, and A.R. Grossman. 1997. The roles of specific xanthophylls in photoprotection. Proc. Natl. Acad. Sci. USA 94:14162-14167.

Sommerburg, O., J.E.E. Keunen, A.C. Bird, and F.J.G.M. van Kuijk. 1998. Fruits and vegeta- bles that are sources for lutein and zeaxanthin: The macular pigment in human eyes. Br. J. Ophthalmol. 82:907-910.

Tracewell, C.A., J.S. Vrettos, J.A. Bautista, H.A. Frank, and G.W. Brudvig. 2001. Carotenoid photooxidation in photosystem II. Arch. Biochem. Biophys. 385:61-69.

USDA National Agricultural Statistics Service. 2008. Statistics by subject, crops and plants, broccoli. 18 June 2009. <http://www.nass.usda. gov/QuickStats/indexbysubject.jsp?PASS_group= crops $\% 20$ and $\% 20$ Plants $>$.

USDA Nutrient Database. 2008. U.S. Department of Agriculture, Agricultural Research Service, National Nutrient Database for Standard Reference, Release 21. 1 Sept. 2008. <http://www. nal.usda.gov/fnic/foodcomp/search/>.

Ye, X.D., S. Al-Babili, A. Kloti, J. Zhang, P. Lucca, P. Beyer, and I. Potrykus. 2000. Engineering the provitamin A ( $\beta$-carotene) biosynthesis pathway into (carotenoid-free) rice endosperm. Sci. 287:303-305. 